\title{
Selection Method of Cross-Border e-Commerce Export Logistics Mode Based on Collaborative Filtering Algorithm
}

\author{
Ying Yang $(\mathbb{D}$ \\ School of Economics, Henan Institute of Technology, Xinxiang, Henan 453003, China \\ Correspondence should be addressed to Ying Yang; yangying@hait.edu.cn
}

Received 17 December 2021; Revised 17 January 2022; Accepted 18 January 2022; Published 10 February 2022

Academic Editor: Miaochao Chen

Copyright ( 2022 Ying Yang. This is an open access article distributed under the Creative Commons Attribution License, which permits unrestricted use, distribution, and reproduction in any medium, provided the original work is properly cited.

\begin{abstract}
The combination of the Internet and foreign trade has promoted the rapid development of cross-border e-commerce, and crossborder e-commerce logistics has risen due to the development of cross-border e-commerce. However, the costs incurred by enterprises in the operation of intermediate logistics links have remained high for many years. Considering the cross-border electricity export logistics mode selection, the author of this paper tackles the main existing problems, using literature study, field survey method, case analysis and the collaborative filtering method of major consumer goods export logistics mode, and the advantages and disadvantages in the enterprise' internal and external environmental analysis and evaluation, and puts forward a scientific logistics coordination mechanism and new export logistics mode. Firstly, the development background of cross-border e-commerce logistics is sorted out, and the research content, research method, and research framework are proposed based on the theoretical research of relevant scholars. Secondly, several logistics modes of cross-border e-commerce export are summarized, including international postal parcel, international express, international special line, etc., and the indicator system of logistics mode selection is determined through comparative analysis of application scope and advantages and disadvantages. Secondly, a logistics selection model based on collaborative filtering algorithm is constructed, and the model is verified by a practical case of a specific export cross-border e-commerce company. Finally, the research conclusions and application strategies of this paper are proposed, so as to provide the most appropriate logistics mode and guarantee suggestions for cross-border e-commerce enterprises and provide ideas and methods for cross-border e-commerce enterprises to choose international logistics mode for different types of import and export goods. The significance of this study was aimed at the current cross-border electricity development mainly by restricting factors, planning the most suitable for the development of China's cross-border electronic business logistics mode, to some extent, and it has enriched the cross-border electricity business related research in the field of logistics, to inspire transformation of foreign trade enterprises, so as to better promote the cross-border electricity business healthy and orderly development and export logistics mode optimization selection.
\end{abstract}

\section{Introduction}

In the era of the global financial crisis, foreign trade as a whole environmental degradation, trade protectionism, the export cost increase, and the international market demand, there appeared many unfavorable factors, such as China's economy developing into the "new normal" China's economy and trade gradually from "importer" into "exporters", especially in China under the favorable policy of "area." It has fully stimulated the vitality of China's import and export trade, and the transaction scale has grown substantially year after year. Cross-border e-commerce exports have ushered in a golden development cycle. Chinese products, with their quality and variety advantages, are occupying more foreign markets [1-3]. However, in the selection of cross-border e-commerce logistics mode, the complex customs clearance process of various countries, long transportation distance, different import and export policies of logistics among different countries, and high logistics costs are the main factors causing long-term and short-term operating losses of cross-border e-commerce enterprises [4]. Expensive intermediate link spending limited support can only be a short period of time for a long time will cause significant economic losses, cross-border electricity only by choosing appropriate 
logistics mode as much as possible to reduce the loss of profit brought by the intermediate links and effectively control the logistics cost, to further improve the profitability, highlighting its core competitiveness. Therefore, it is an important means to greatly improve the efficiency of crossborder e-commerce industry to solve the problem of choosing the export logistics mode of major consumer goods for cross-border e-commerce enterprises [5, 6].

It is mainly a process of flow control and management of cross-border e-commerce goods and information by way of sea, land, and air. Cross-border e-commerce logistics is an extension of domestic e-commerce logistics, which involves the flow of goods across the border and is the indispensable last [7-9]. Cross-border e-commerce logistics improves the efficiency of cross-border e-commerce by establishing crossborder e-commerce networks and facilities, so as to ensure the efficient operation of the whole industry chain of crossborder e-commerce [10]. Meanwhile, there are also problems such as high logistics cost, low informatization of parcels, difficulty to guarantee damage, complicated customs clearance procedures, and difficulty to solve returned goods. Nowadays, a single logistics link and service function are no longer enough to meet the needs of domestic and foreign consumers for cross-border logistics, so it is a top priority to build a complete cross-border e-commerce industry chain system. Cross-border e-commerce is a cross-border business activity. Therefore, cross-border e-commerce logistics should adjust measures to local conditions and choose appropriate cross-border logistics mode according to different cross-border businesses and market changes.

Cross-border logistics involves a long distance, a long time, export costs, export tariffs, and other issues [11]. Some scholars have divided the cross-border e-commerce logistics mode into three types: "single," "transfer at both ends," and "receiving at both ends." They believe that the intellectualization of system and information is the most important technical element in the process of cross-border e-commerce logistics. Logistics mode is the specific form and operation guide of cross-border e-commerce logistics. Different logistics modes have their own applicable characteristics, advantages, and disadvantages. In cross-border e-commerce trade activities, foreign trade enterprises should choose the appropriate logistics mode according to their own business conditions [12-15]. The correct choice is directly related to the cost and efficiency. At present, analytic hierarchy process is often used to build logistics mode selection model, which can achieve better practical effect. However, analytic hierarchy process is only applicable to a simple logistics environment, and the calculation results are not accurate in the face of complex e-commerce links.

In view of the existing major problems in the selection of cross-border e-commerce export logistics mode, this paper firstly describes the analysis of cross-border e-commerce logistics mode and the construction of index system, then discusses the basic principle of collaborative filtering algorithm, and finally verifies the selection and optimization of cross-border e-commerce export logistics mode through an example. The main innovation point is to take the crossborder e-commerce logistics model as the entry point, in- depth analysis of the operation of small and medium-sized cross-border e-commerce enterprises of different sizes in the market, from the four perspectives of business sharing, information sharing, overseas warehouse resources sharing, and reverse logistics sharing to achieve the optimized development of cross-border export.

\section{Cross-Border E-Commerce Logistics Model Analysis and Index System Construction}

Logistics services generally involve two or more customs, which are divided into three parts: domestic logistics, international transportation, and logistics distribution in destination countries. In the process of seizing the international market, how to choose logistics for cross-border e-commerce export should be considered first: cost, destination, speed, convenience, and risk, especially cost. At the same time, different enterprises should choose the appropriate logistics mode according to the enterprise size, product characteristics, consumer groups, business model, and other factors and analyze various logistics solutions [16].

At present, international postal parcel is the logistics mode with the most complete coverage network. It can send mail to more than 220 countries with post offices around the world, with strong regional adaptability and far strategic positioning. International postal parcel has the advantages of low cost, wide regional coverage, high national policy support, high security, strict inspection and quarantine, and clear strategic positioning, but at the same time, it has the disadvantages of low timeliness, low security, and restriction by the weight, shape, volume, and other factors of the parcel [17]. Therefore, when choosing international postal parcels as export logistics channels, enterprises should comprehensively consider whether the port of receipt and delivery, the value of goods, timeliness, safety, and other requirements of goods are met.

International commercial express is a logistics mode widely used in the current cross-border e-commerce export. IT has its own global transportation network and powerful IT and logistics system. Its biggest characteristic is fast aging, but at the same time, the freight is relatively expensive [18]. It has the advantages of high timeliness of logistics channels, high safety of product transfer, good service, and high national policy support and clear strategic positioning. However, it also has the following advantages: The requirements for products are relatively high, restricted items cannot be transported, logistics costs are high, and a variety of additional costs are added. Due to the single operation mode, only low-price slow delivery and high-price express delivery mode, railway cannot adapt to the diverse needs of consumers, so its market share is gradually falling.

Cross-border railway logistics is the present domestic cross-border e-commerce "peer-to-peer" transport and is the most convenient logistics mode; this kind of logistics mode of transport in the land of departure and arrival, routes, and time basically is fixed, adopted in domestic package warehouse model, and then sends the goods in bulk to a particular country or region, finally in relying on local cooperation Courier to deliver the goods to the hands of 
consumers. It is a good logistics mode for cross-border e-commerce export enterprises with fixed lines. Logistics is faster than international postal service, and logistics costs are lower than international express. Besides, it provides customs clearance services with high efficiency, which will not cause inventory overstocking. Its disadvantage lies in the regional limitations of logistics services, only for large volume [19].

Overseas warehouse model is the current domestic emerging of cross-border e-commerce service and is the most convenient logistics mode; this kind of logistics mode to make self-built or lease warehouse abroad and in advance by the export seller or a third party platform will deliver the goods by land, sea, and air transportation way to them, the last shipment directly from outside warehouse to order products distribution to clients. As a major breakthrough in the development of cross-border e-commerce, overseas warehouse has unique advantages that postal route and special line mode do not have, such as logistics cost and logistics timeliness. However, the construction, leasing, and operation of overseas warehouses require manpower, which is not suitable for all e-commerce enterprises [20].

Transshipment mode is the most perfect logistics mode for domestic comprehensive business. This logistics mode can be regarded as a combination of cross-border special line logistics and overseas warehouse mode, which is mainly aimed at crossborder, multiple orders, and high frequency [21]. In China, containerized transport has a containerized process, which can achieve large-scale effect to save transportation costs. However, its biggest advantage is that it is not limited by transportation destination like cross-border logistics special lines.

Table 1 is the comparison of five export modes. It can be seen from the table that international commercial express is mainly applicable to goods with extremely sensitive timesensitive due to its characteristics of fast aging, high transshipment cost, and multiple shipping restrictions. International small postal parcels are mainly applicable to light and small e-commerce parcels of less than $2 \mathrm{~kg}$, targeted at serving e-commerce customers, and the order value is generally not more than 50 dollars. They are mainly used for goods with light weight, small size, and low price that consumers do not have high requirements on logistics. Cross-border private line logistics mode is suitable for $3 \mathrm{~kg}$ small goods with internal subparts, the first way to collect goods, and the last way to distribute. Overseas warehouse mode is generally applicable to sellers who need to prepare goods in advance and have moderate limitation requirements, and the goods are mainly heavy goods of more than $20 \mathrm{~kg}$. The lumped transshipment mode is suitable for the goods with insensitive time and low value and not easy to be deformed in the logistics process.

The selection of appropriate logistics mode will be affected by many factors including timeliness, cost, and security and so on. The selection of appropriate evaluation index system will directly affect the scientificity. The construction principles of the indicator system mainly follow the following five principles: representativeness, system flexibility, independence, hierarchy, and availability. In this article mainly from the scale of cross-border logistics enterprise itself and operation ability, overseas customer service level, product characteristics, logistics costs, and service quality, legal policy direction factor analysis was carried out on the index selection, cross-border operation ability, its scale and logistics business enterprise overseas customer service levels, tea characteristics, and legal policy. After fully mastering the construction principles of the index system and the influencing factors of index selection, this paper determines the total cost of cross-border logistics, customer service level, logistics operation ability, informatization level, logistics enterprise scale, and strength as the first-level evaluation indicators [22]. In transportation and delivery cost, storage cost, operation and management cost, artificial cost, safety, response time, customer service attitude, product tracking, complaint rate, accuracy, transport aging, damage and packet loss rate, job readiness, warehousing, transportation, order management, process management, enterprise employees, enterprise users, the corporate profitability, the enterprise scale, asset scale, and enterprise transport network scale are 22 indicators as secondary evaluation indicators.

Let us say we have a set of subjects $N=\{i=1,2, \ldots, n\} . S$ is a subset of $N$, which represents the cooperative alliance that may be formed between the subjects and is the characteristic function of forming the cooperative alliance, representing the benefits obtained through the cooperative alliance.

$$
\begin{aligned}
& \left\{\begin{array}{l}
V\left(\phi_{i}\right)=0 \\
V\left(S_{1} \cup S_{2}\right) \geq V\left(S_{1}\right)+V\left(S_{2}\right), S_{1} \cap S_{2}=\phi_{i},
\end{array}\right. \\
& \phi_{i}=\sum W(|S|)\left[V(S)-V\left(\frac{S}{i}\right)\right] \\
& W(|S|)=\frac{(n-|S|) !(|S|-1) !}{n !},
\end{aligned}
$$

where $|S|$ is the number of elements in the set $S, W(|S|)$ is the weighting coefficient, $V(S / i)$ is the revenue obtained by the cooperative alliance after removing members $i$, and $V(S)-$ $V(S / i)$ is the revenue contribution of members $i$.

The benefit distribution result obtained in the above step is the cost saving part of each cooperative member, and the cost saving of each member after the establishment of cooperative alliance is subtracted from the cost of individual decision making, which is the cost sharing result.

In this way, starting from the logistics service needs of customers, it is decomposed step by step, and logistics service providers with superior resources in each link cooperate with each other to meet customer needs, which forms a value chain. In this value chain, logistics service integrators shoulder. Value chain logistics mode is emphasized, powered by the logistics needs of customers, effective integration of logistics resources, and the increase in the overall supply chain efficiency and reduces logistics costs, seeking to meet service level, at the lowest cost of the raw material suppliers, manufacturers, logistics companies, distributors and retailers combined effectively, and the 
TABle 1: Comparison of five export logistics modes of cross-border e-commerce.

\begin{tabular}{lccccc}
\hline $\begin{array}{l}\text { Indicators/ } \\
\text { modes }\end{array}$ & $\begin{array}{c}\text { International } \\
\text { postal packet }\end{array}$ & $\begin{array}{c}\text { International } \\
\text { commercial express }\end{array}$ & Cross-border dedicated logistics & $\begin{array}{c}\text { Overseas } \\
\text { position model }\end{array}$ & $\begin{array}{c}\text { Consolidation } \\
\text { transshipment mode }\end{array}$ \\
\hline Logistics cost & Medium & Highest & Higher & Lower & Lower \\
Clearance ability & Strongest & Strong & Medium & Weaker & Weaker \\
Coverage area & Widely & Widely & Weaker & Ordinary & Weaker \\
Transit time & Slow & Fastest & Faster & Fast & Ordinary \\
Service quality & Weaker & High & Ordinary & Ordinary & Ordinary \\
\hline
\end{tabular}

pursuit of efficiency and reduces the cost of the whole logistics system.

\section{Basic Principle of Collaborative Filtering Algorithm}

Collaborative filtering algorithm is one of the most studied recommendation algorithms and the widest range of application; the basic idea is for a particular user to find user groups with similar interests, according to the group of interest for a particular user to recommend mainly using the similarity between user demand, automatic filtering, and screening the right goods or services to customers [23, 24]. The idea is simple: if users have similar interests, they are likely to have similar needs for information services. The implementation of collaborative filtering has the following steps: firstly, to obtain user information, that is, to obtain users' evaluation of certain information items; secondly, similarities between users are analyzed and preferences of specific users for certain information are predicted. In this method, the model is not established, but the whole user item score data set is used to generate recommendations [25].

Various functions to calculate similarity have been proposed. Let the scores of items $i$ and $j$ in $m$-dimensional user space be vectors $i$ and $j$, respectively; then, the similarity between the two items is calculated as follows:

$$
\operatorname{sim}\left(u, u^{\prime}\right)==\frac{\sum_{i \in I_{u, u^{\prime}}}\left(R_{u, i}-\bar{R}_{u}\right)\left(R_{u^{\prime}, i}-\bar{R}_{u^{\prime}}\right)}{\sqrt{\sum_{i \in I_{u, u^{\prime}}}\left(R_{u, i}-\bar{R}_{u}\right)^{2}} \sqrt{\sum_{i \in I_{u, u^{\prime}}}\left(R_{u^{\prime}, i}-\bar{R}_{u^{\prime}}\right)^{2}}},
$$

where $I_{u, u^{\prime}}$ represents the intersection of users $u$ and $u^{\prime}$ items selected or purchased, $R_{u, i}$ represents the average preference degree of users $u$ and $u^{\prime}$ selecting or purchasing items, and $\operatorname{sim}\left(u, u^{\prime}\right)$ represents the similarity degree of users $u$ and $u^{\prime}$.

Then, the nearest neighbor group of the specified users is selected. In general, the prediction results can be calculated using the following formula:

$$
P_{a, j}=\vec{u}_{a}+\frac{\sum_{b=1}^{N}\left(u_{b}-\vec{u}_{b}\right) \times \operatorname{Sim}_{a, b}}{\sum_{b=1}^{N} \operatorname{Sim}_{a, b}}
$$

where $P_{a, j}$ represents the user's $a$ preference for the project $i$ and $\operatorname{Sim}_{a, b}$ represents the similarity of users $u_{a}$ and $u_{b}$.

User-based collaborative filtering can classify users according to the similarity of users' evaluation of projects through mutual assistance among users and find the neighbors of target users, thus obtaining more accurate recommendation results [26-28]. Secondly, in the userbased system filtering system, all users can benefit from the evaluation of neighbor users. As long as each user contributes to the system, the system can maintain better performance. Role consistency performance promotes the benign development of collaborative filtering system and keeps the system effective recommendation. Finally, it can realize strange discovery. Any single recommendation algorithm has its drawbacks [29].

The perspective of collaborative filtering based on items is based on the similarity between items. It can not only improve the measurability of recommendations, but also provide a better explanation for the recommendation results, because most of the time, specific users are often interested in some specific products. However, project-based collaborative recommendation cannot make "cross-type" recommendation, because it always recommends similar projects, so it cannot tap the potential interests of users [30].

Model-based collaborative filtering can build users and projects into models by mining in the process of model construction and finally predict projects that have not been rated by the model and then recommend results that meet users' corresponding preferences. In terms of noise reduction and recommendation accuracy, the application model is the most sensible choice, which attracts more and more researchers to carry out corresponding research. Several collaborative filtering algorithms, such as model-based linear regression model, probability model, Bayesian model, and clustering model, are covered.

Evaluation indexes are used to measure the recommendation performance of collaborative filtering algorithm, which is mainly reflected in prediction quality and recommendation quality. Mean absolute error (MAE) and coverage are commonly used to measure the prediction quality of the algorithm. Accuracy and recall are commonly used to measure recommendation quality [31].

The smaller the MAE value is, the higher the prediction quality is. Suppose there are $n$ items in the system, the score set predicted by the algorithm is $\left\{p_{1}, p_{2}, \ldots, p_{n}\right\}$, and the corresponding actual score set is $\left\{r_{1}, r_{2}, \ldots, r_{n}\right\}$, MAE calculation formula is as follows:

$$
\text { MAE }=\frac{\sum_{i=1}^{N}\left|p_{u i}-q_{u i}\right|}{N} .
$$

Coverage index calculates the ratio of predicted items to all unscored items, so as to measure the comprehensiveness of prediction. Assuming that $h$ items are predicted, the calculation method of coverage is as follows: 


$$
\operatorname{Cov}=\frac{h}{n}
$$

Precision is not only used to evaluate system performance in information retrieval field, but also used to measure accuracy in recommendation system. In a recommendation system, precision represents the ratio of the number of predicted scores of the algorithm equal to the actual score value of the user to the total number of predicted scores. Precision's calculation is as follows:

$$
\text { precision }=\frac{\text { Hits }}{N}=\frac{\mid \text { test } \cap \text { Top }-N \mid}{N},
$$

where Hits is the number of predicted score values of the algorithm equal to the real score value in the test set, $N$ is the total number of predicted scores, and test is the number of scores in the test set.

Recall index is also used to evaluate the system effect in the field of information retrieval. The larger Recall value is, the better the recommendation quality of the algorithm is.

$$
\text { recall }=\frac{\text { Hits }}{\mid \text { test } \mid}=\frac{\mid \text { test } \cap \text { Top }-N \mid}{\mid \text { test } \mid} \text {. }
$$

In order to verify the clustering effect of user attributes, the contour coefficient $S$ is used to evaluate the clustering result, and the specific expression is

$$
S(i)=\frac{b(i)-a(i)}{\max \{a(i), b(i)\}},
$$

where $a(i)$ and $b(i)$ represent the average distance in its cluster. The direct trust between the two is as follows:

$$
\operatorname{DTrust}(a, b)=\frac{\left|I_{a} \cap I_{b}\right|}{\left|I_{a} \cup I_{b}\right|} .
$$

In order to alleviate the impact of differences in actual scores between users on user trust relationship [32], the mean value of the scoring difference between the two users on the common scoring items is calculated as follows:

$$
\varepsilon=\frac{\sum_{i \in I_{a} \cap I}\left(\left|c_{a i}-c_{b i}\right|\right)}{\left|I_{a} \cap I_{b}\right|} .
$$

Advantages of collaborative filtering: collaborative filtering can predict places that users have not used or visited with higher accuracy, and recommendation accuracy will increase with the increase of users' ratings. In real life, the number of users and the projects will continue to increase, but with the corresponding evaluation matrix of data, it did not get the same level of growth; it is relatively sparse data to itself more sparse and has reached a corresponding calculation and processing of the data standard; it also does not know how to start treatment. The same goes for cold starts. Collaborative filtering studies and excavates users' interests by referring to historical behavior, which makes it relatively easy for users who want to hack into and inject fake data, thus affecting the results presented in the final recommendation list.

\section{Calculation Results Are Analyzed and Discussed}

A company was founded in 2010, the registered capital is 1 million yuan, the specialty is engaged in the first jewelry, copper jewelry accessories, copper beads, agio, needles and tubes, and all kinds of jewelry accessories, various kinds of materials, and related copper wire, steel wire, etc. The production and sales of series jewelry accessories are sold all over the country. At the same time, it is also a fixed supplier of many foreign trade companies, and the products are sold to the world. However, in foreign trade under the new situation, there is a marked increase in the domestic labor cost and other factors, the rise of emerging economies, and the global jewelry market share's continuous erosion; at the same time, the domestic jewelry price competition is intense, cross-border electricity enterprise should avoid homogeneity competition, and transformation and upgrading is imperative. Through field interviews and visits to company A's physical stores, we know that most of the company's exported jewelry and accessories are copper jewelry and copper jewelry accessories. The volume of goods is small and the value is high, the price is high, and the logistics cost is relatively small. At the same time, due to the fashion elements of jewelry, customers are highly responsive to logistics services. Therefore, when company A chooses logistics mode, the first consideration is the availability of logistics services, the second is the service responsiveness required by customers and the proportion of logistics costs, and the last is other influencing factors. Therefore, the logistics mode selection process of company A is shown in Figure 1.

To sum up, the weight of the evaluation index system is as follows: customer service level $>$ total cost of cross-border logistics $>$ logistics operation capacity $>$ scale and strength of logistics enterprises $>$ informatization level. Export cross-border electrical contractor self-built overseas warehouse model including the position and the characteristics of high operating costs, and storage items and variety, suitable for choosing selfbuilt model of cross-border electronic business enterprise type, mainly includes the main consumption goods and enjoys a certain international well-known large cross-border electricity enterprises, adopts the localization strategy of cross-border electricity enterprise special commodities and sales of large cross-border electronic business enterprise. The cross-border e-commerce enterprises suitable for the third-party overseas warehouse mode mainly include medium-sized with medium brand awareness, large sales volume, and low value-added products and those that have just set foot in overseas warehouse business and have certain brand awareness in China but low awareness abroad. The characteristics of one-stop supporting service mode include low initial investment, low business risk, and simple operation process. The clustering results of different initial values are shown in Figure 2.

The ranking of the total correlation analysis values of the four international logistics modes is obtained from the figure. The higher the correlation analysis value is, the closer it is to the ideal international logistics mode, and its advantages and disadvantages can be obtained. According to 


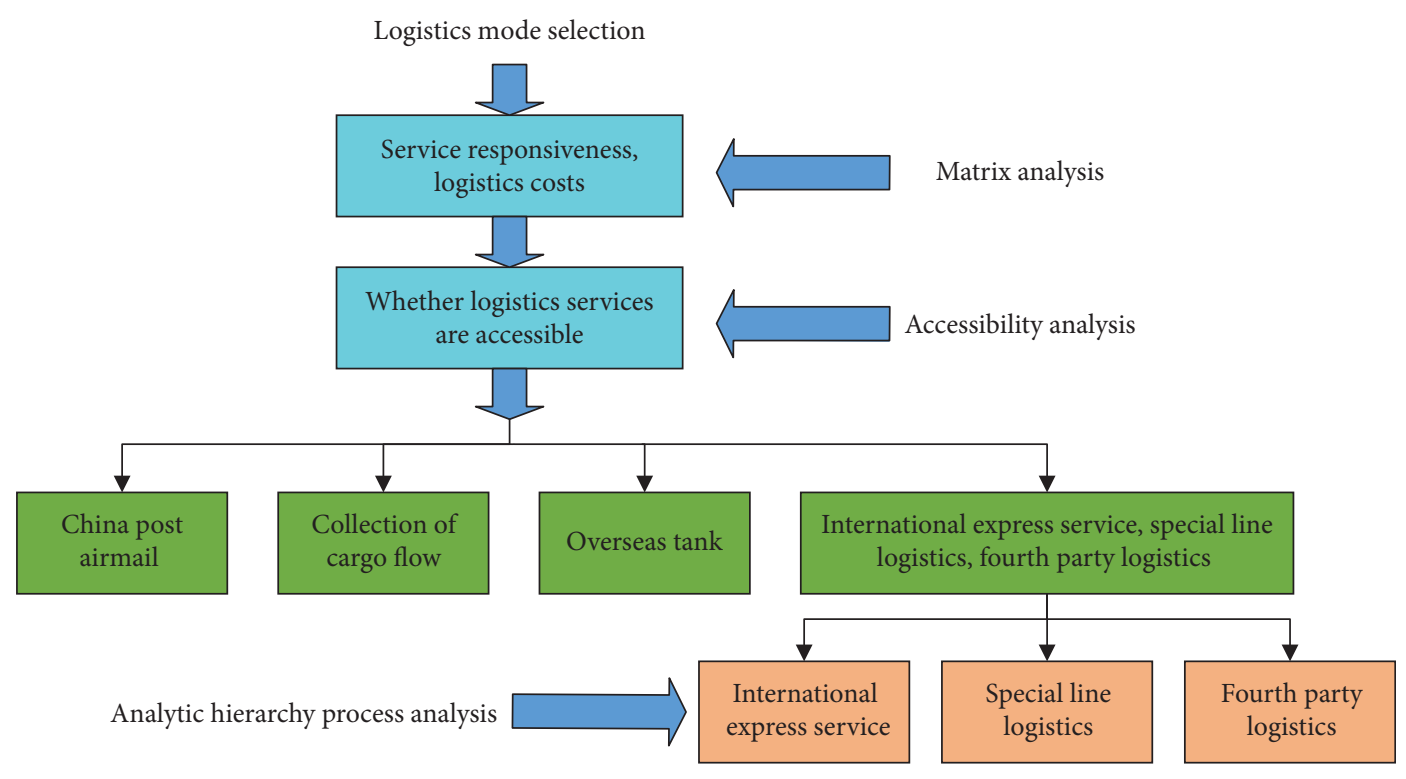

FIgURE 1: Logistics mode selection process of company A.
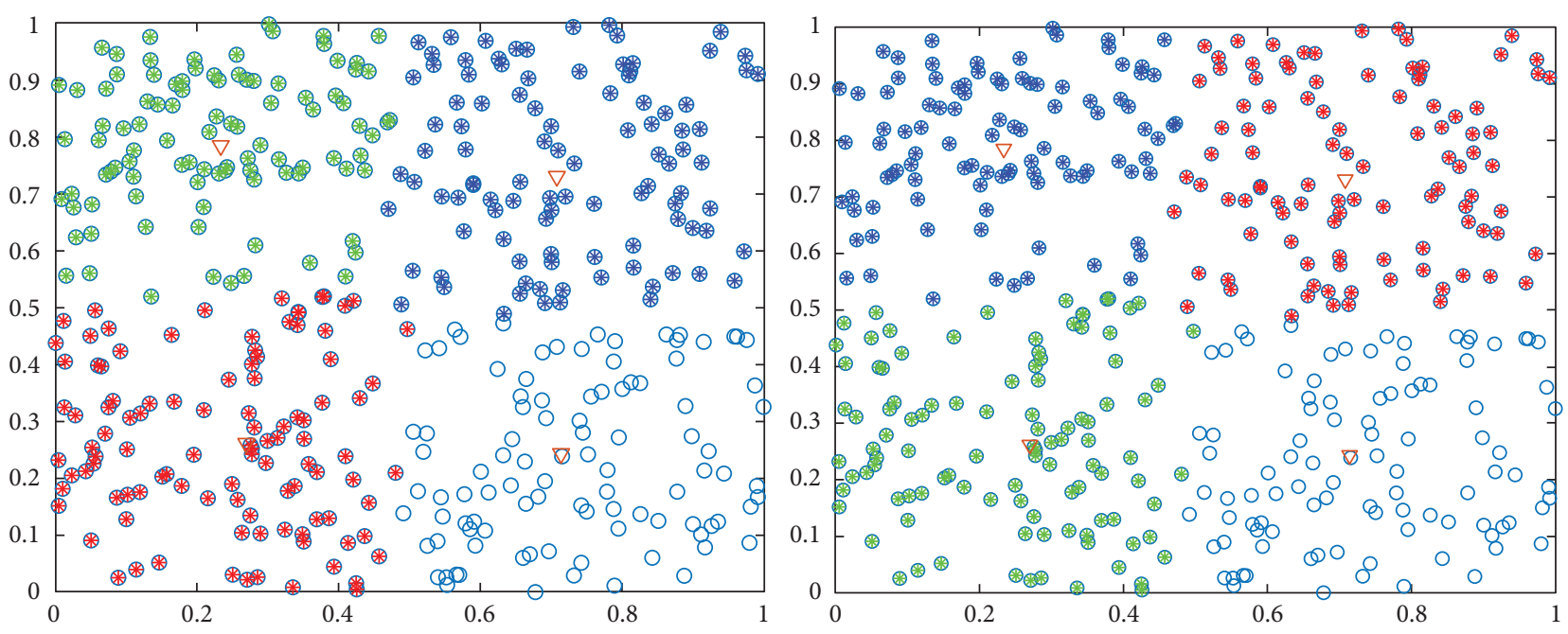

FIGURE 2: Clustering results of different initial values.

the results of collaborative filtering algorithm analysis and comprehensive evaluation model, it can be seen that crossborder e-commerce enterprises should first consider the cost when choosing cross-border logistics mode. The customer service level affects the reputation of enterprises and the secondary purchase of consumers and plays a vital role in the survival and development of enterprises. Therefore, the customer service level ranks second, and its conclusion is consistent with the reality, so as to verify the scientificity and feasibility of the comprehensive evaluation model in this paper and provide a method for the selection of international logistics mode of cross-border e-commerce. At the same time, it provides targeted suggestions for China's development of international logistics and optimization of international logistics mode, which is helpful for cross-border ecommerce to choose the appropriate overseas warehouse mode. Cross-border logistics mode selection chart under single-objective multiobjective decision making is shown in Figures 3 and 4, respectively.

Comprehensive evaluation of different cross-border logistics modes is shown in Figure 5. As we see the model of establishing cross-border logistics alliance has the highest score. It can be preliminarily concluded that establishing logistics alliances with other platforms is more suitable for the long-term development needs of company A. Currently in the "area" under the background of construction, the need for more electricity enterprises and logistics enterprises involved a company alone to "solo" difficulty to deal with the complex situation of international trade and cross-border logistics environment, which requires electricity logistics enterprises to establish the development mechanism of mutual coordination and mutual assistance, build a unified cross-border logistics industry standards, and focus on the advantages of the domestic company to achieve collective 


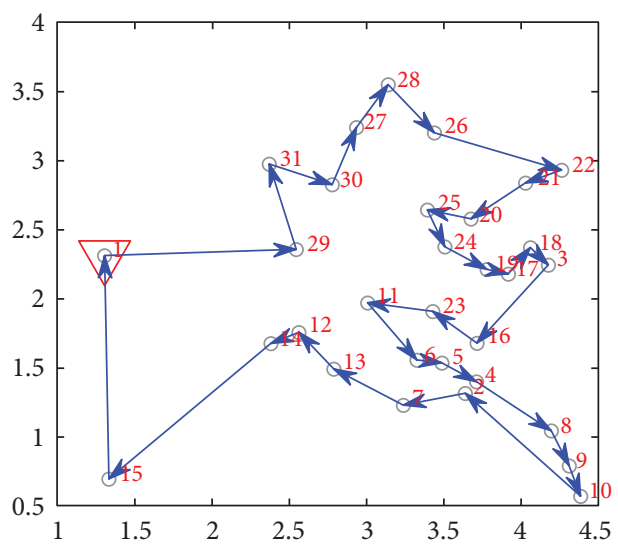

Figure 3: Cross-border logistics mode selection chart under single-objective decision making.

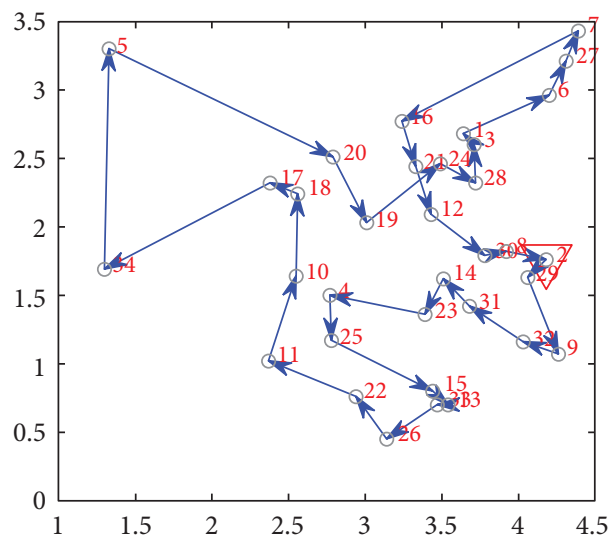

Figure 4: Cross-border logistics mode selection chart under multiobjective decision making.
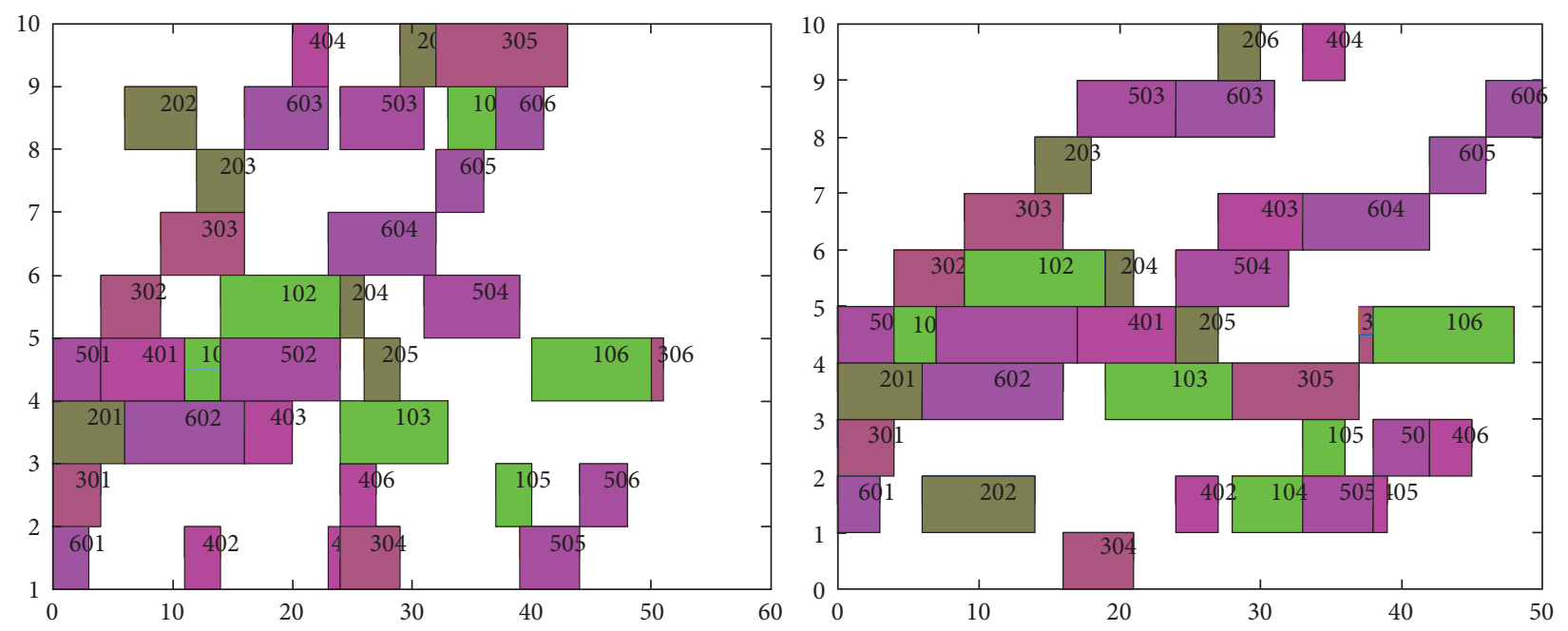

Figure 5: Comprehensive evaluation of different cross-border logistics modes.

development. Therefore, the choice of "cross-border logistics alliance mode" is a logistics mode that conforms to the current development trend, but also focuses on the future.
International commercial express has the highest comprehensive score of 87.281 among the five logistics modes, which is the most suitable logistics mode for 

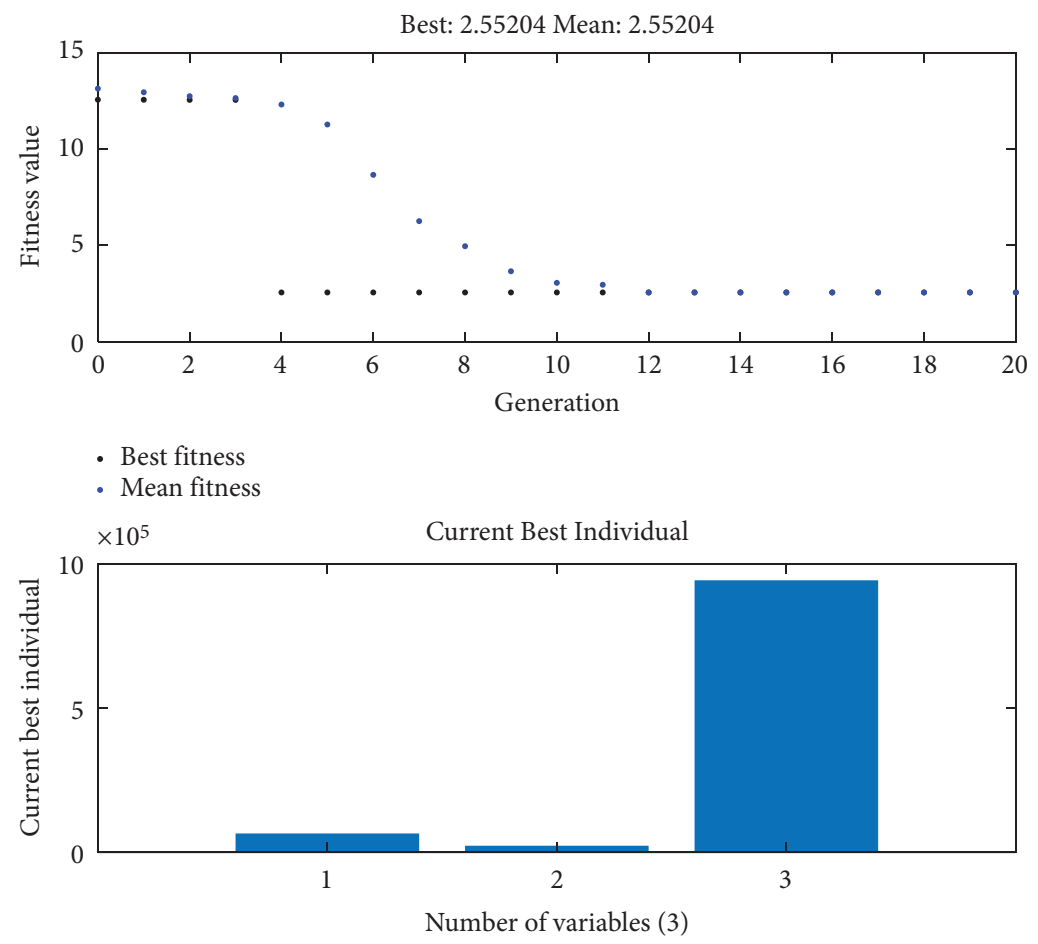

Figure 6: Parameter impact on the recommendation system.
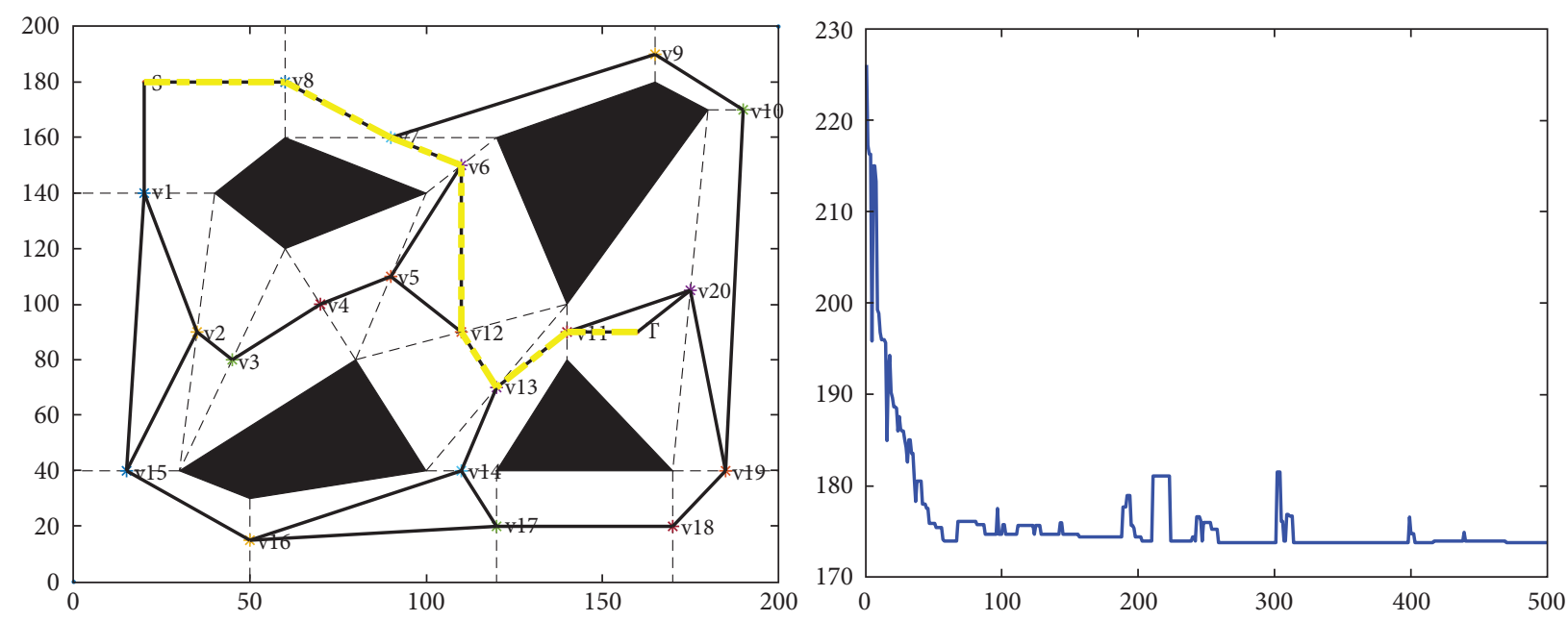

FIGURE 7: Cloud model visualization results.

companies' consumer goods export business. The score of overseas warehouse mode is 86.3132 , indicating that overseas warehouse mode is also more suitable export business and can be considered as a priority mode for companies to expand business overseas. It is worth noting that the weight value of total cross-border logistics cost and customer service is relatively high, which is 0.3298 and 0.3869 , respectively, while the weight value of informatization level is relatively low, which is 0.0545 , indicating that companies only pay attention to some superficial key points while ignoring some hidden key points. It also reflects that crossborder e-commerce companies only focus on product production and processing, shop operation, and lack of understanding of logistics processes. Parameter impact on the recommendation system is shown in Figure 6.

To this end, cross-border e-commerce companies should subdivide logistics channels, priority adjustment of international high-end consumer customers belonging to the region of logistics distribution mode. At the same time, strengthen cooperation with leading enterprises, establish industrial strategic alliance, strong combination, and complementary advantages. Finally, change the existing talent strategy, cultivate professional and technical personnel in production and operation positions, and introduce high-end compound talents in management positions. The visualization results of the cloud model are shown in Figure 7. 


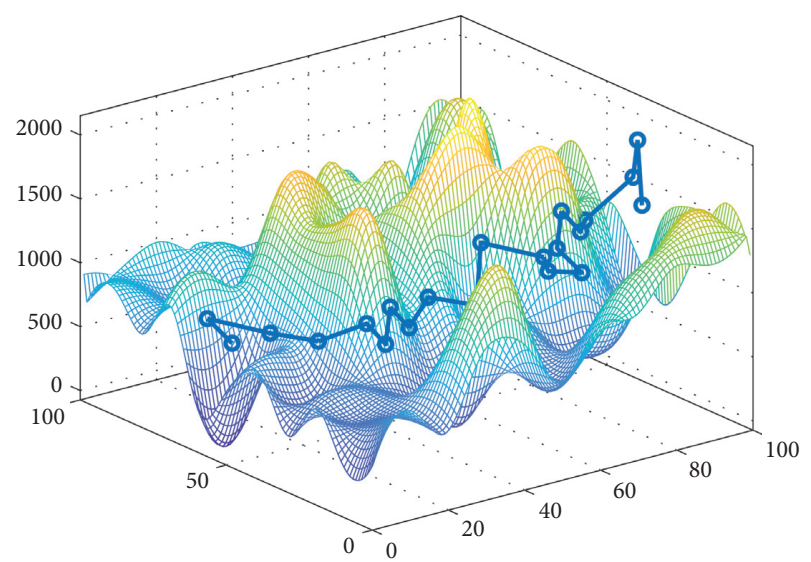

FIgURE 8: Trend of algorithm accuracy.

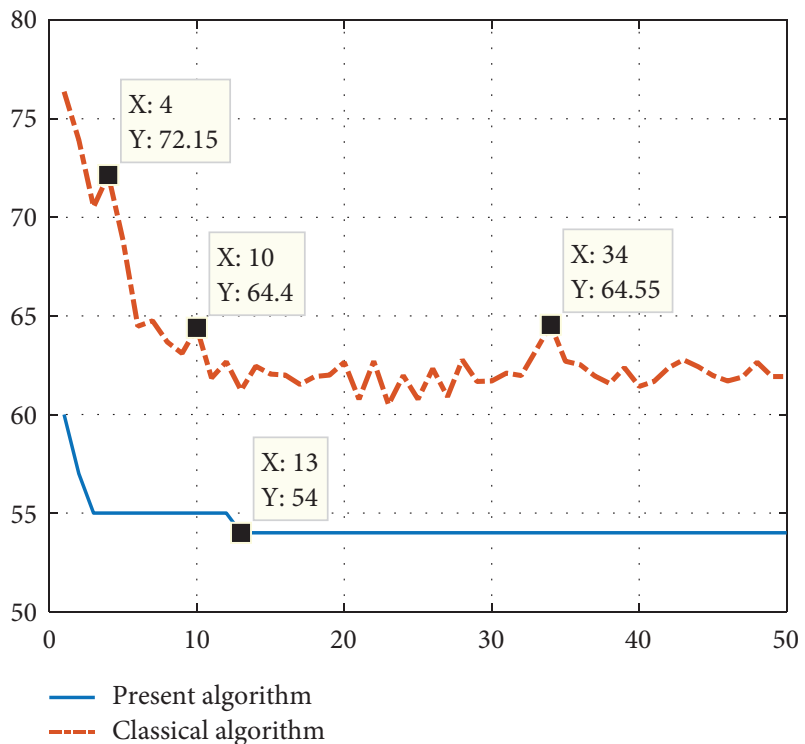

FIGURE 9: MAE comparison between the proposed algorithm and the classical algorithm.

When choosing different logistics modes, we need to consider the three factors of total logistics cost, total profit, and customer satisfaction. In order to take the long-term benefits of each logistics mode into account, we choose a time span of two years. Enterprise decision makers determine the weight of total logistics cost, total profit, and customer satisfaction. The possible profit amount of the enterprise in the new market in the next two years and the total cost required by each logistics mode are predicted to obtain the logistics benefit value and customer satisfaction under each logistics mode. The business scope of dedicated logistics and overseas warehouse is smaller than that of postal parcel and international express, so the sales volume is relatively low. The timeliness of overseas warehouse is high, so customer satisfaction is better than the other three logistics modes. The timeliness of postal parcel is poor, and there is a certain loss rate, so customer satisfaction is the worst. Trend of algorithm accuracy is shown in Figure 8.
A logistics mode can not meet the requirements of all products, often requiring a combination of a variety of logistics mode, storage, and highest score which is most suitable for overseas, followed by the international express delivery business; set scale after cargo transportation, international postal parcel scored the lowest, international postal parcel is not the most suitable for cross-border logistics mode, but the actual situation of China's cross-border logistics is that international postal parcels account for about $70 \%$ of the market share, so for company $\mathrm{A}$, in order to reduce logistics costs, improve customer service level, enhance competitiveness, and enhance the overall strength of the enterprise, it needs to optimize the combination of crossborder logistics modes. Improve the ability of overseas demand assessment and prediction, cultivate international vision, strengthen the control of the target overseas market, and adopt the mode of overseas warehousing when the platform has overseas warehouses and the products are marketable. For regions without overseas warehouses, the mode of international express logistics can be adopted for the products with high requirements on logistics timeliness. For the areas where the international express cannot reach or the express cost is very expensive, the large-scale transport after collection and the form of international postal parcel transport can be adopted. MAE comparison between the proposed algorithm and the classical algorithm is shown in Figure 9.

\section{Conclusion}

Cross-border electricity becomes an important means of China's foreign trade and global trade activities, and crossborder electricity logistics becomes the important carrier of cross-border electricity, only by constantly improving crossborder electricity environment international logistics mode. With the explosive growth of cross-border e-commerce exports, the industry development dilemma is gradually recognized by enterprises. This paper takes cross-border e-commerce logistics mode as the starting point and preliminarily determines the research ideas of this paper. First of all, the development background is collected and sorted out, and the research content, research method, and research framework of this paper are proposed based on the theoretical research of relevant scholars. Secondly, several logistics modes are analyzed and compared. Through comparative analysis of advantages and disadvantages, the indicator system of logistics mode selection is determined. Then, the logistics selection model based on collaborative filtering algorithm is constructed, and the weight coefficients of all indicators are calculated quantitatively by MATLAB. Finally, the export cross-border electricity company A is used as a practical case to verify the model. The following suggestions are put forward from business sharing, information sharing, overseas warehouse resource sharing, and reverse logistics to realize the optimized development.

(1) In terms of logistics cost, the rank of the four logistics modes from superior to inferior is as follows: overseas warehousing, fourth-party logistics, 
international postal service, and international express. In terms of logistics efficiency, the order from best to worst is as follows: overseas warehousing, international express, third-party logistics, and international postal service. In terms of logistics restrictions, the order from superior to inferior is the following: overseas warehousing, fourth-party logistics, international express, and international postal service. In terms of comprehensive risks, the ranking from best to worst is the following: fourthparty logistics, international express, international postal business, and overseas warehousing.

(2) For the industrial chain they are in, correctly choose the logistics mode suitable for the industrial chain. Cross-border electricity companies tend to be engaged in a variety of consumer products of export business; each kind of consumer goods of the industrial chain link, in the face of the international customer demand, as well as the target area and level of development will be different, so by efficient handling inventory, warehousing, order processing, logistics, and other related links, integrate the best resources.

(3) Cross-border electricity enterprise should fully understand the company's products industry type, correct selection, and product industry types that meet the needs of logistics mode, from the logistics mode, logistics services, and logistics costs, improve customer satisfaction, to improve business ability, and set up suitable unified cross-border electrical logistics distribution system. Only in this way can the level of coordinated development of cross-border e-commerce and international logistics be improved and the efficient and guaranteed operation be ensured.

Due to the limitations of research conditions, knowledge reserve, research ability, and other subjective reasons, there are some aspects to be improved and perfected in this study, mainly including the following aspects: (1) at present, China's cross-border e-commerce logistics modes mainly include postal parcel, international express, special line logistics, and overseas warehouse. With the in-depth development of crossborder e-commerce, more cross-border logistics modes will inevitably emerge, such as the fourth party logistics mode. (2) When considering the optimization selection of cross-border e-commerce logistics mode, this paper only starts from a theoretical perspective and does not take into account the specific situation of countries or cross-border e-commerce platforms. (3) The calculation of cost allocation model of joint use of overseas warehouses for distribution services is more complicated and needs further optimization and transformation. (4) The cost analysis based on the optimal inventory of overseas warehouse may become the research point.

\section{Data Availability}

The data used to support the findings of this study are available from the corresponding author upon request.

\section{Conflicts of Interest}

The author declares that there are no conflicts of interest.

\section{References}

[1] Y. H. Hsiao and M. C. Chen, "Logistics service design for cross-border e-commerce using kansei engineering with textmining-based online content analysis," Telematics and Informatics, vol. 13, no. 11, pp. 11-18, 2016.

[2] M. B. Ribadu and N. W. Wan, "An integrated approach towards Sharia compliance E-commerce trust," Applied Computing and Informatics, vol. 15, pp. 1-6, 2019.

[3] T. Van Asch, W. Dewulf, F. K. Ivan, C. Eddy, and V. de Voorde, "Cross-border e-commerce logistics-Strategic success factors for airports," Research in Transportation Economics, vol. 3, pp. 167-192, 2017.

[4] Á. Valarezoa, T. Pérez-Amaralb, T. Garín-Muñozc, I. H. Garcíab, and R. Lópezb, "Drivers and barriers to crossborder e-commerce: evidence from Spanish individual behavior," Telecommunications Policy, vol. 42, pp. 464-473, 2018.

[5] A. Jazairy, J. Lenhardt, and R. von Haartman, "Improving logistics performance in cross-border 3PL relationships," International Journal of Logistics Research and Applications, vol. 20, no. 5, pp. 491-513, 2017.

[6] Y. Guo, Y. Bao, B. J. Stuart, and K. Le-Nguyen, “To sell or not to sell: exploring sellers' trust and risk of chargeback fraud in cross-border electronic commerce," Information Systems Journal, vol. 28, no. 2, pp. 359-383, 2018.

[7] G. H. Gesner, "Cross-border E-commerce and logistics mode innovation," Research in Transportation Business \& Management, vol. 12, no. 3, pp. 21-35, 2015.

[8] G. Alexandridis, G. Siolas, and A. Stafylopatis, "Enhancing social collaborative filtering through the application of nonnegative matrix factorization and exponential random graph models," Data Mining and Knowledge Discovery, vol. 6, pp. 1-29, 2017.

[9] A. Tom, "Strategic, tactical and decision in multi-national logistics network: review and discussion of modeling issue," International Journal of Production Research, vol. 7, pp. 1501-1523, 2015.

[10] S. B. Paul, "Multi-criteria decision making method for thirdparty logistics evolution," 2010 Second International Conference on Engineering System Management and Applications, vol. 12, pp. 16-34, 2016.

[11] L. Zhu, The Institutional Environment for Global E-Commerce Diffusion: A Cross-Country Investigation, Long Island University, Brookville, CF, USA, 2015.

[12] G. Ndubizu, "Legal determinants of the global spread of international logistics model," International Journal of Information, vol. 11, pp. 181-194, 2015.

[13] Q. Yuan, "The construction mechanism and algorithm of cross border E-commerce export logistics mode from the perspective of value chain," Journal of Intelligent and Fuzzy Systems, vol. 37, no. 3, pp. 3393-3400, 2019.

[14] Y.-M. Zheng and C. Zhang, "The impact of cross-border e-commerce on China's agricultural products export: an empirical study based on big data processing," in Proceedings of the 2020 International Conference on Big Data and Social Sciences, pp. 106-110, ICBDSS, Xi'an, China, August 2020.

[15] H. R. Boveiri, R. Khayami, M. Elhoseny, and M. Gunasekaran, "An efficient Swarm-Intelligence approach for task scheduling in cloud-based internet of things applications," Journal of 
Ambient Intelligence and Humanized Computing, vol. 10, no. 9, pp. 3469-3479, 2019.

[16] P. Zhang, D. Wang, and J. Xiao, "Improving the recommender algorithms with the detected communities in bipartite networks," Physica A: Statistical Mechanics and Its Applications, vol. 471, pp. 147-153, 2017.

[17] A. Marchand and P. Marx, "Automated product recommendations with preference-based explanations," Journal of Retailing, vol. 7, no. 1, pp. 48-52, 2020.

[18] S. Kant and T. Mahara, "Merging user and item based collaborative filtering to alleviate data sparsity," International Journal of System Assurance Engineering \& Management, vol. 9, no. 1, pp. 1-7, 2018.

[19] N. Zhang and Z. Wang, "Collaborative filtering recommendation algorithm based on hybrid similarity," in Recent Developments in Intelligent Computing, Communication and Devices, P. Srikanta and J. Vipul, Eds., pp. 617-625, Springer, Singapore, 2019.

[20] W. Alnumay, U. Ghosh, and P. Chatterjee, "A trust-based predictive model for mobile ad hoc network in internet of things," Sensors, vol. 7, no. 1, pp. 142-146, 2019.

[21] Z. Zhang, G. Xu, P. Zhang, and Y. Wang, "Personalized recommendation algorithm for social networks based on comprehensive trust," Applied Intelligence, vol. 47, no. 3, pp. 659-669, 2017.

[22] S. K. Mydhili, S. Periyanayagi, and S. Baskar, "Machine learning based multi scale parallel K-means++ clustering for cloud assisted internet of things," Peer-to-Peer Networking and Applications, vol. 13, no. 2, pp. 568-571, 2020.

[23] F. M. Haper and J. A. Konstan, "The MovieLens datasets," ACM Trans on Interactive Intelligent System, vol. 5, no. 4, pp. 1-19, 2016.

[24] B. Poerwanto, "Evaluating the K-Means analysis in clustering area based on estates productivity in tana luwu using silhouette index," Journal of Physics: Conference Series, vol. 1752, no. 1, pp. 256-260, 2021.

[25] C. Kaleli, "An entropy-based neighbor selection approach for collaborative filtering," Knowledge-Based Systems, vol. 56, pp. 273-280, 2014.

[26] H. Li, J. Cui, B. Shen, and J. Ma, “An intelligent movie recommendation system through group-level sentiment analysis in Microblogs," Neurocomputing, vol. 210, pp. 164173, 2016.

[27] J. Nan, J. Tao, and D. Juan, "Personalized recommendation based on customer preference mining and sentiment assessment from a Chinese e-commerce website," Electronic Commerce Research, vol. 1, pp. 1-21, 2018.

[28] F. O. Isinkaye, Y. O. Folajimi, and B. A. Ojokoh, "Recommendation systems: principles, methods and evaluation," Egyptian Informatics Journal, vol. 16, no. 3, pp. 261-273, 2015.

[29] H. Yan, Y. Jiang, and Z. Gao, "Exploring hidden factors behind online food shopping from amazon reviews: a topic mining approach," in Proceedings of the Agricultural \& Applied Economics Association Meeting, pp. 1-26, Chicago, IL, USA, July 2017.

[30] S. Sondur, A. Chigadani, and S. Nayak, "Similarity measures for recommender systems: a comparative study," Journal of Research, vol. 2, no. 3, pp. 76-80, 2016.

[31] F. Dafedar and K. F. Bharati, "A fast collaborative filtering approach for web personalized recommendation system," in Proceedings of the 2017 International Conference on Information Communication and Embedded System, pp. 1-7, Chennai, India, February 2017.
[32] F. M. Almutairi, N. D. Sidiropoulos, and G. Karypis, "Context-aware recommendation-based learning analytics using tensor and coupled matrix factorization," IEEE Journal of Selected Topics in Signal Processing, vol. 11, no. 5, pp. 729-741, 2016. 